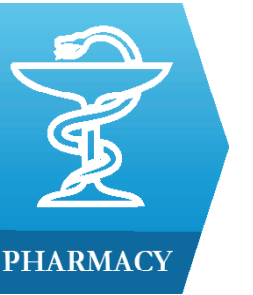

\title{
Evaluation of spermicidal activity of saponosides from Saponaria officinalis / Caryophyllaceae, Glycyrrhizia glabra / Fabaceae and Herniaria glabra / Caryophyllaceae
}

\author{
Mohamed Réda Sefrioui ${ }^{1}$, Ibrahim Sbai El Othmani ${ }^{1}$, Halima Filali ${ }^{1}$, \\ Sanae Derfoufi ${ }^{1}$, Soufiane Derraji ${ }^{2}$, Adnane Benmoussa ${ }^{1}$, \\ Amal Ait Haj Said ${ }^{1}$
}

1) Laboratory of Drug Science, Biomedical and Biotechnological Research, Faculty of Medicine and Pharmacy, Hassan II University of Casablanca, Casablanca, Morocco

2) Laboratory of PharmacologyToxicology, Faculty of Medicine and Pharmacy, Mohamed V University in Rabat, Rabat, Morocco

DOI: $10.15386 / \mathrm{mpr}-1879$

Manuscript received: 29.08 .2020

Received in revised form: 30.10 .2020

Accepted: 24.11.2020

Address for correspondence:

r.sefrioui@hotmail.fr

This work is licensed under a Creative Commons Attribution-NonCommercialNoDerivatives 4.0 International License

\begin{abstract}
Background and objective. Chemical spermicides currently marketed and widely used are known to have many side effects. Thereby, and in order to look for more tolerated natural spermicidal agents, the aim of this work was to evaluate the spermicidal potential of saponin extracts from the roots of Saponaria officinalis / Caryophyllaceae, Glycyrrhizia glabra / Fabaceae, and Herniaria glabra / Caryophyllaceae by studying their in vitro effects on sperm mobility and vitality.

Methods. Methanolic saponin extracts from the plants roots were performed. Sperm suspensions were prepared by centrifugation on a PureSperm ${ }^{\circledR}$ density gradient $(70$ and $45 \%)$ and incubated with various concentrations of saponin extracts $(50,250$, 500 and $750 \mu \mathrm{g} / \mathrm{mL}$ ) at $37^{\circ} \mathrm{C}$. The spermicidal activity was evaluated by studying the mobility and vitality of spermatozoa at different time intervals ranging from 10 to 240 minutes.

Results. A dose and time dependent effect on sperm mobility and vitality was observed for our extracts.

Extracts from Saponaria officinalis roots induced an irreversible immobilization and a total non-viability of sperm within 10 minutes at a concentration of $750 \mu \mathrm{g} / \mathrm{mL}$. A similar effect was observed within 30 minutes at $750 \mu \mathrm{g} / \mathrm{mL}$ for Herniaria glabra extract and within 90 minutes at $500 \mu \mathrm{g} / \mathrm{ml}$ for Glycyrrhizia glabra extract.

Conclusion. The results of our study showed that the saponin extracts of our plants roots possess potent in vitro dose and time dependant spermicidal effect. These natural products could therefore represent a safer and better tolerated alternative to chemical spermicides.
\end{abstract}

Keywords: spermicidal activity, Saponaria officinalis / Caryophyllaceae, Glycyrrhizia glabra / Fabaceae, Herniaria glabra / Caryophyllaceae

\section{Background}

The World Health Organization has recognized sexual and reproductive health as a human right [1]. With the use of methods that allow women to plan and space their pregnancies, health indicators have improved [1]. Many general and local contraceptive methods are available today [2]. These methods are hormonal, natural, or based on physical or chemical barriers [3]. The estrogen-progestogen combination is the most effective hormonal method, when used correctly [4]. Natural or traditional methods aim to regulate births without using a drug or medical device. They include the method of withdrawal or coitus interruptus [4], the Ogino method, known as the "calendar" method [5], the body temperature method [6], the cervical 
mucus method or the "Billings" method [6], the method of breastfeeding and amenorrhea [6] and the urinary strips of Luteinizing Hormone (LH) [7]. Barrier methods, physical (male and female condoms, diaphragms, cervical caps) or chemical (spermicides), prevent fertilization [6]. However, spermicides have numerous side reactions, including tingling and irritation effects such as burning, itching or a rash and also genital ulcers that can increase the risk of sexually transmitted diseases [6]. In addition, spermicides containing 9-nonoxynol are contraindicated in cases of infections or risk of HIV [6].

Saponosins are heterosides formed of a watersoluble carbohydrate chain and a triterpene or steroid liposoluble structure $[8,9]$. They are widely present in the plants kingdom [8]. The classical definition of saponins is based on their surfactant properties [10].

These secondary metabolites have been proven to possess many pharmacological activities including antiinflammatory, immunomodulatory, and anticancerigen properties [9,11-13]. Saponins are also recommended in the treatment of hypercholesterolaemia [14]. The saponosides of certain plants are also being studied for their potential spermicidal effect and could be used in contraceptive formulations $[15,16]$.

Glycyrrhizia glabra L / Fabaceae, better known under the name liquorice in French or sweet-wort in English, is a herbaceous plant that can reach more than a meter in height [17]. Its stems are flowering, erect with alternate, compound, imparipinnate, bright green leaves [18]. Its papilionaceous flowers are pale blue and grouped in erect clusters [17]. The fruit is a flattened pod (1.5 - 2.5 $\mathrm{cm})$, strangled between the seeds $[17,18]$. Glycyrrhizia glabra contains 0.6 to $2 \%$ flavonoids (chalcones, flavanones, flavanolols, isoflavones, isoflavans), 3 to $15 \%$ of triterpene saponins (glycyrrhizin), coumarins (coumarin, herniarine, umbelliferone, glycocoumarin, glycocoumarin, glycocoumarin), phytosetrols, carbohydrates, and volatile aromatic compounds [19,20].

Saponaria officinalis L / Caryophyllaceae, or Saponaria vaccaria L, is known as Hameteras in English or saponary and Lychnis officinalis in French [21,22]. It is an herbaceous plant, 70 to $80 \mathrm{~cm}$ tall, with an orange to brown twig rhizome, and a tuft of erect stems [21]. The leaves are opposite, large, oval, lanceolate, marked with three to five veins [23]. The flowers are pink or pinkish white, arranged in a cyme. The fruit is an oval capsule containing small seeds $[21,23]$. The whole plant contains resinous substances, mucilaginous matters, flavonoids and saponins [21,23]. The underground parts of Saponaria officinalis contain 5 saponins (triterpene saponosides), giving gypsogenin by hydrolysis [21,23]. They also contain carbohydrates [21].

Herniaria glabra / Caryophyllaceae is also known by its French name: Herniaire or Turquette or by its
English name: Glabrous rupturewort, Smooth rupturewort or Green carpet [24]. It is a perennial plant, 5 to $20 \mathrm{~cm}$ long, glabrous, light green, with a small or thin root [25]. The stems are slender, lying down and spreading [25]. The leaves are glabrous, oblong or lanceolate, attenuated at the base and opposite [24]. The flowers are very small, sessile and form multiflorous, oblong glomeruli, arranged in clusters [25]. Herniaria Glabra contains 3 to $9 \%$ of triterpene saponins derived from medicagenic, gypsogenic and 16- $\alpha$-hydroxymedicagenic acid and bidesmoside saponosides branched on the C28 carboxyl [26]. It also contains 0.2 to $1.2 \%$ of flavonoids derived from quercetol and isorhamnetol (Hyperoside) and 0.1 to $0.4 \%$ of coumarins (umbelliferone, herniarine) [26].

Our study aims to assess the spermicidal potential of saponosides extracted from the roots of Glycyrrhizia glabra, Saponaria officinalis and Herniaria glabra. The objective is to look for natural, non toxic and well tolerated spermicides, suitable in particular for women in whom hormonal contraception is contraindicated.

\section{Methods \\ Study strategy}

This work was carried out in two stages. The extraction and preparation of saponins extracts took place in the laboratory of drug sciences, biomedical and biotechnological research of the Faculty of Medicine and Pharmacy of Casablanca (Morocco). Then, the evaluation of the spermicidal activity took place in the laboratory of medical analyses "LABOMAC" in Casablanca (Morocco).

\section{Preparation of plants for saponins extraction}

Saponosides were extracted from $250 \mathrm{~g}$ of the dry roots of three plants: Glycyrrhiza glabra / Fabaceae, Herniaria glabra / Caryophyllaceae and Saponaria officinalis / Caryophyllaceae. These roots were previously ground into a fine powder using a grinder "Premium line 13 pulverisette disc mill (Fritsch GmbH Grinding and Grain size)".

The identification of plants was made by the pharmacognosy department of the Faculty of Medicine and Pharmacy, Casablanca (Morocco). The voucher number is Gg-F22-1963 for Glycyrrhiza glabra / Fabaceae, $\mathrm{Hg}-\mathrm{C} 19-1926$ for Herniaria glabra / Caryophyllaceae and So-C43-1922 for Saponaria officinalis / Caryophyllaceae. The storage was made in hermetically sealed jars, away from light and heat.

\section{studied}

Characterization of saponins in the plants

An aqueous extract (decocted at 1\%) from each plant was prepared according to the following protocol: in a $250 \mathrm{~mL}$ flask, $1 \mathrm{~g}$ of plant powder and $100 \mathrm{~mL}$ of distilled water were mixed. After boiling for 20 to 30 $\mathrm{min}$, the extract was filtered with filter paper in a $100 \mathrm{~mL}$ erlenmeyer flask and the filtrate was allowed to cool. 
Table I. Dilution range for each extract prepared.

\begin{tabular}{|l|c|c|c|c|c|c|c|c|c|c|c|}
\hline Tube $\mathbf{N}^{\circ}$. & $\mathbf{1}$ & $\mathbf{2}$ & $\mathbf{3}$ & $\mathbf{4}$ & $\mathbf{5}$ & $\mathbf{6}$ & $\mathbf{7}$ & $\mathbf{8}$ & $\mathbf{9}$ & $\mathbf{1 0}$ & $\mathbf{1 1}$ \\
\hline Decocte $(\mathrm{mL})$ & 0 & 0.5 & 1 & 1.5 & 2 & 2.5 & 3 & 3.5 & 4 & 4.5 & 5 \\
Distilled water (mL) & 10 & 9.5 & 9 & 8.5 & 7 & 7.5 & 7 & 6.5 & 6 & 5.5 & 5 \\
Content of vegetable drugs (\%) & 0 & 5 & 10 & 15 & 20 & 25 & 30 & 35 & 40 & 45 & 50
\end{tabular}

The presence of saponins was determined by a foam test. For every extract, a dilution sequence of concentrations from 0 to $50 \%$ was prepared (Table I). Then, each tube was closed and shaken vigorously in a horizontal position for 15 seconds. After 10 min at rest, the height of foam formed was measured. This height represents the foam index and the concentration giving a foam index of $1 \mathrm{~cm}$ will be determined.

Preparation of plant extracts for the study of spermicidal activity

Two hundred grams of vegetable powder, previously prepared, were defatted by pentane, for 24 hours. The residue obtained after filtration would be subjected to three extractions with $250 \mathrm{~mL}$ methanol. The three filtrates were mixed. The methanol was evaporated by means of a rotary evaporator at $40{ }^{\circ} \mathrm{C}$. The concentrated residue was dried in open air. Then, $1 \mathrm{~g}$ of this residue was dissolved in $100 \mathrm{~mL}$ of methanol and then $100 \mathrm{~mL}$ of ethyl ether were added to precipitate the residue again. The precipitate recovered by filtration was dried in open air.

\section{Sperm samples used for the study}

The study of spermicidal activity was carried out using 90 sperm samples, collected at the "LABOMAC" medical analyses laboratory. These samples were collected after the classic spermogram analyses.

Only normal sperm samples (according to the reference values for the semen parameters established by the WHO) were used in our study. These criteria were determined as follows: After liquefaction at $37{ }^{\circ} \mathrm{C}$ for $30 \mathrm{~min}$, the sperm analyzed must have at least 20 million counts per $\mathrm{mL}$ and a progressive mobility of at least $50 \% 60$ minutes after ejaculation. The sperms were then treated according to the separation technique, with a density gradient of PureSperm ${ }^{\circledR} 70 \%$ and $40 \%$. The final pellet obtained would be used to study the spermicidal activity of the plant extracts.

\section{extracts}

Study of the spermicidal activity of plant

The spermicidal activity of plant extracts was studied at different concentrations. A dilution range was prepared from an initial $1 \mathrm{mg} / \mathrm{mL}$ stock solution. The concentrations prepared were $50,250,500$ and $750 \mu \mathrm{g} /$ $\mathrm{mL}$. Then, $100 \mu \mathrm{L}$ of each extract concentration was added to $100 \mu \mathrm{L}$ sperm sample previously treated (final pellet). The spermicidal activity was evaluated at regular time intervals, from $10 \mathrm{~min}$ to $4 \mathrm{~h}$. It was based on the study of the mobility and vitality of sperm. Mobility was analyzed by light microscopy to determine the percentage of mobile and immobile spermatozoa in the sample. The vitality was estimated by the eosin test. This test consists in mixing $20 \mu \mathrm{L}$ of treated sperm with an equal volume of $1 \%$ eosin. The percentage of viable and non-viable spermatozoa (colored heads) is determined by counting at least 100 spermatozoa per sample.

\section{Data analysis}

The results were recorded on an Excel ${ }^{\circledR}$ database and we used percentages calculation to determine the qualitative and quantitative results variables.

\section{Results} studied

Demonstration of saponosides in the plants

The foam index determination allowed to assess the saponoside content in our sample. The height of the foam was measured for each dilution (Figure 1). extracts

Study of the spermicidal activity of plant

Sperm mobility was evaluated after the action of the different extracts on the sperm samples. A total and instant spermicidal effect was observed at the concentration of $750 \mu \mathrm{g} / \mathrm{mL}$, for the three plant extracts.

At the concentration of $500 \mu \mathrm{g} / \mathrm{mL}$, more than $90 \%$ of the spermatozoa lost their movements and became completely immobile after 10 min (Figures 2, 3, 4). For the control, only $5 \%$ of the spermatozoa become immobile after 10 min (Figure 5).

At a concentration of $500 \mu \mathrm{g} / \mathrm{mL}$, all of the spermatozoa present in the sample acquired slow movements, they became immobile after $30 \mathrm{~min}$.

For a concentration of $250 \mu \mathrm{g} / \mathrm{mL}$, the mobility of the spermatozoa was suppressed after $90 \mathrm{~min}$ for Herniaria glabra and Saponaria officinalis (Figures 2, 3), and after $3 \mathrm{~h}$ for Glycyrrhizia glabra (Figure 4).

At a low concentration $(50 \mu \mathrm{g} / \mathrm{mL})$ the spermicidal appeared more slowly, the spermatozoa were immobilized after $3 \mathrm{~h}$ for Saponaria officinalis, and after $4 \mathrm{~h}$ for Herniaria glabra (Figures 2, 3).

Sperm vitality was assessed using the eosin test. It revealed an increase in death rate. 


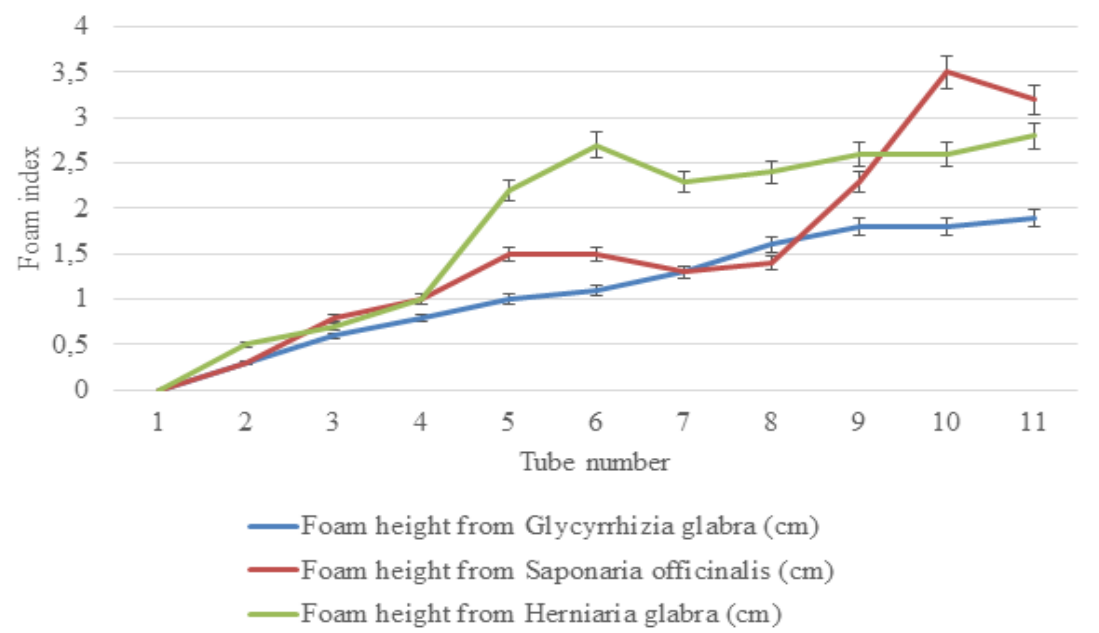

Figure 1. Assessment of foam height for each plant saponins extract.

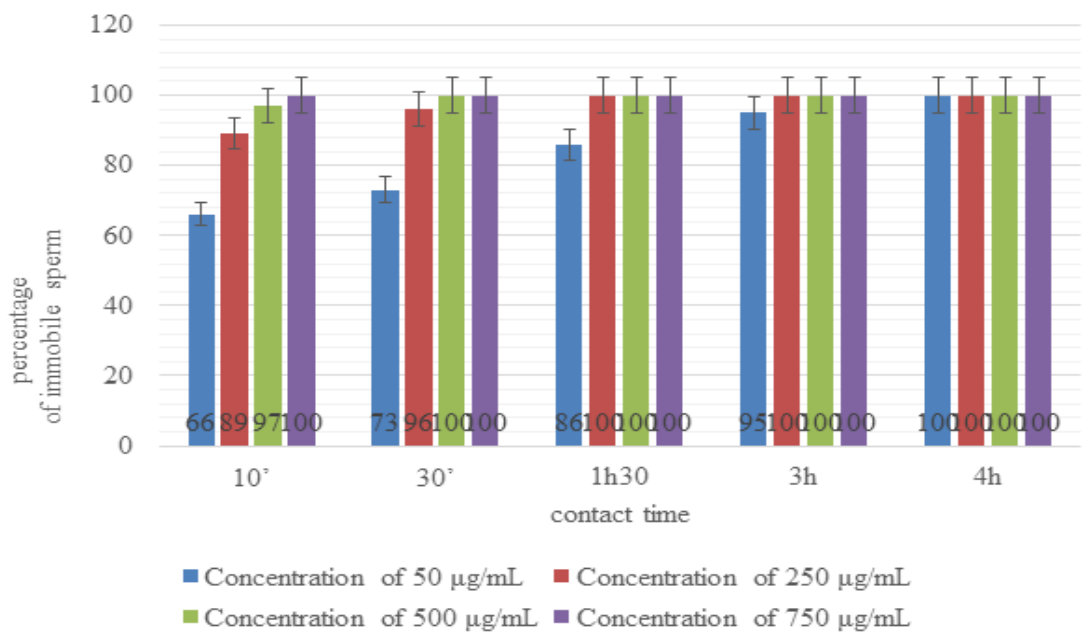

Figure 2. Evaluation of the mobility of the sperm as a function of time and concentration of the extract of Herniaria glabra.

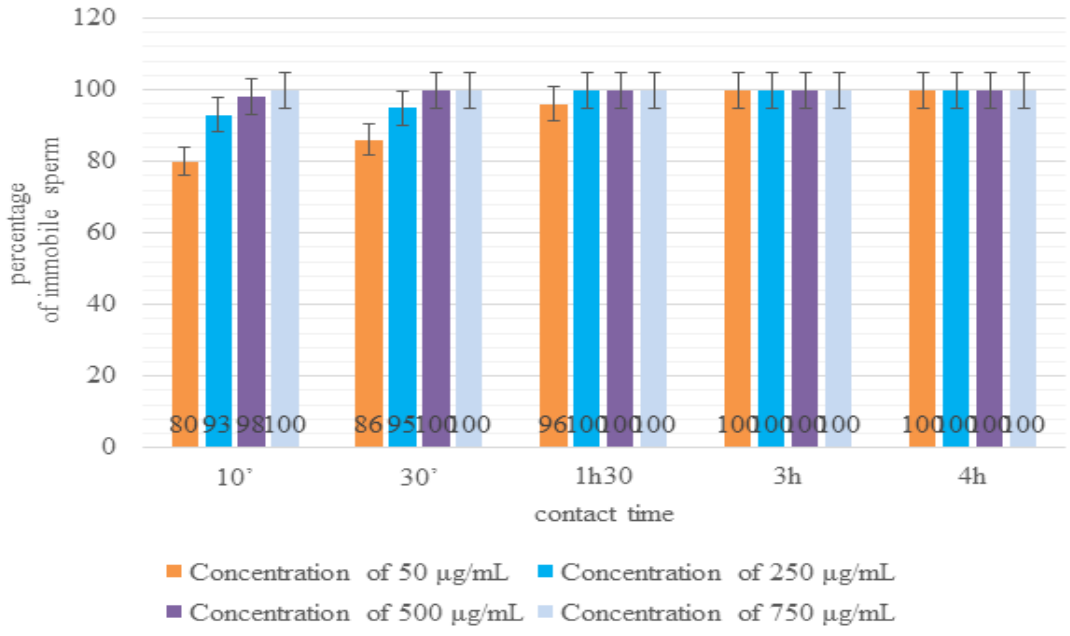

Figure 3. Evaluation of the mobility of the sperm as a function of time and concentration of the extract of Saponaria officinalis. 


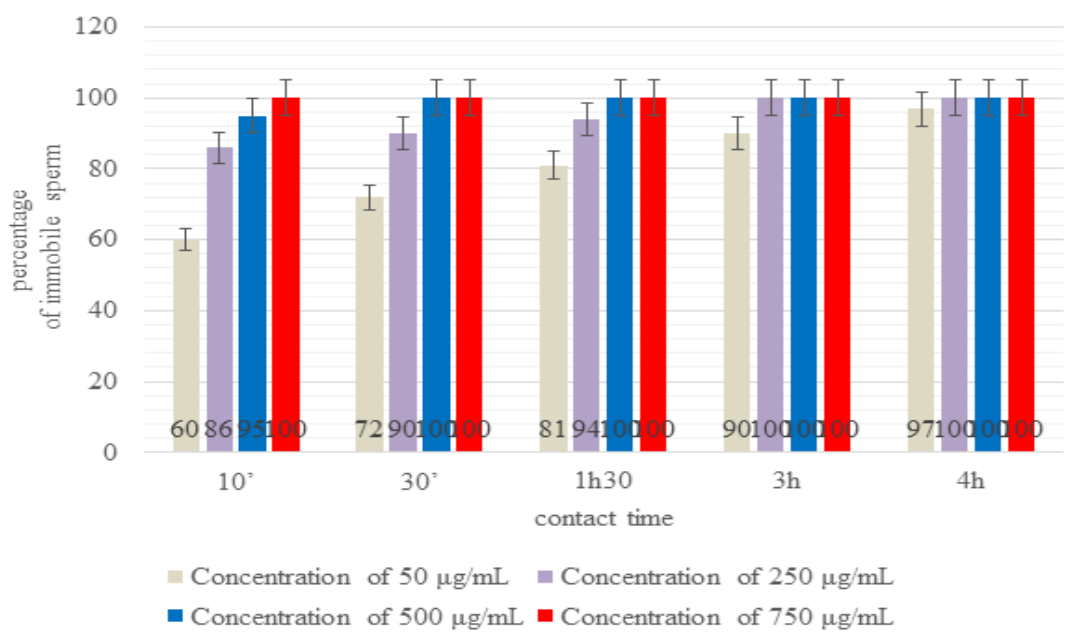

Figure 4. Evaluation of the mobility of the sperm as a function of time and concentration of the extract of Glycyrrhizia glabra.

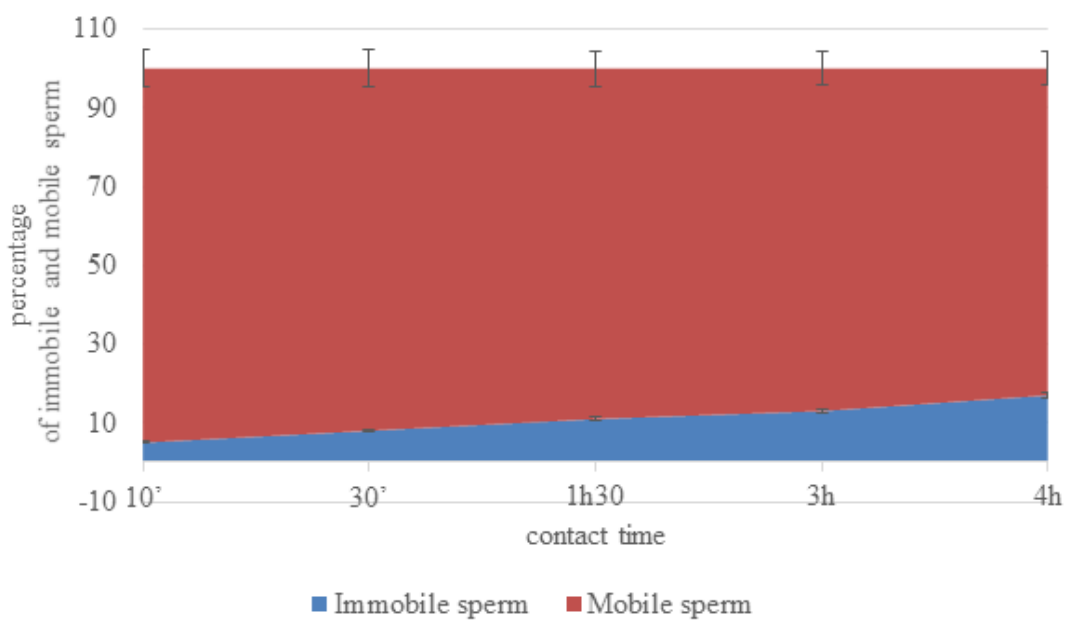

Figure 5. Evaluation of the mobility of the sperm as a function of time for the control sample.

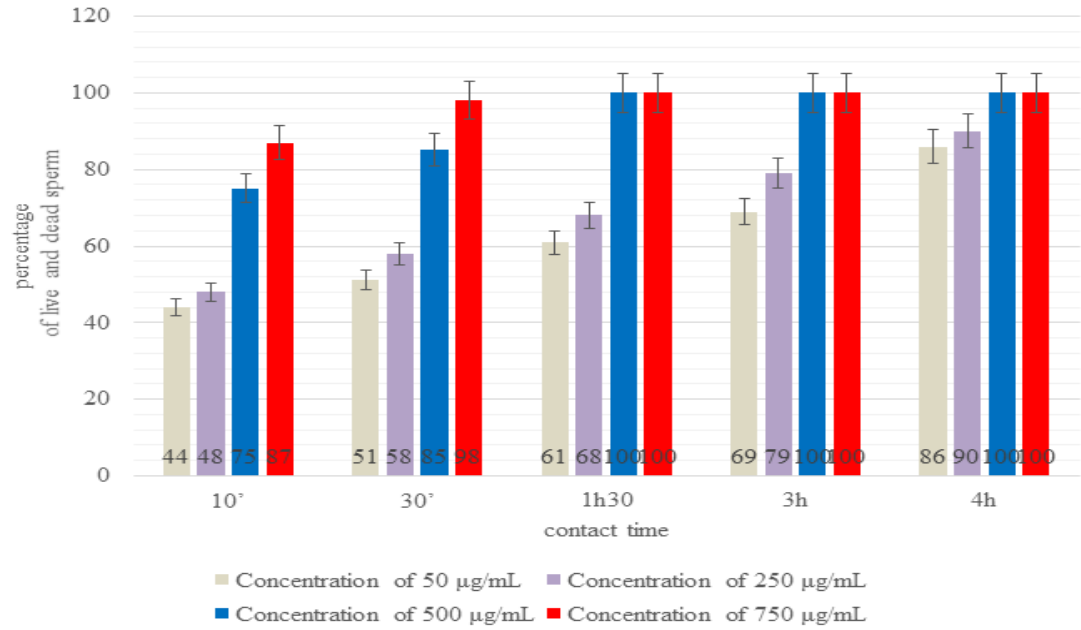

Figure 6. Evaluation of the vitality of the sperm as a function of time and the concentration of the extract of Glycyrrhizia glabra. 


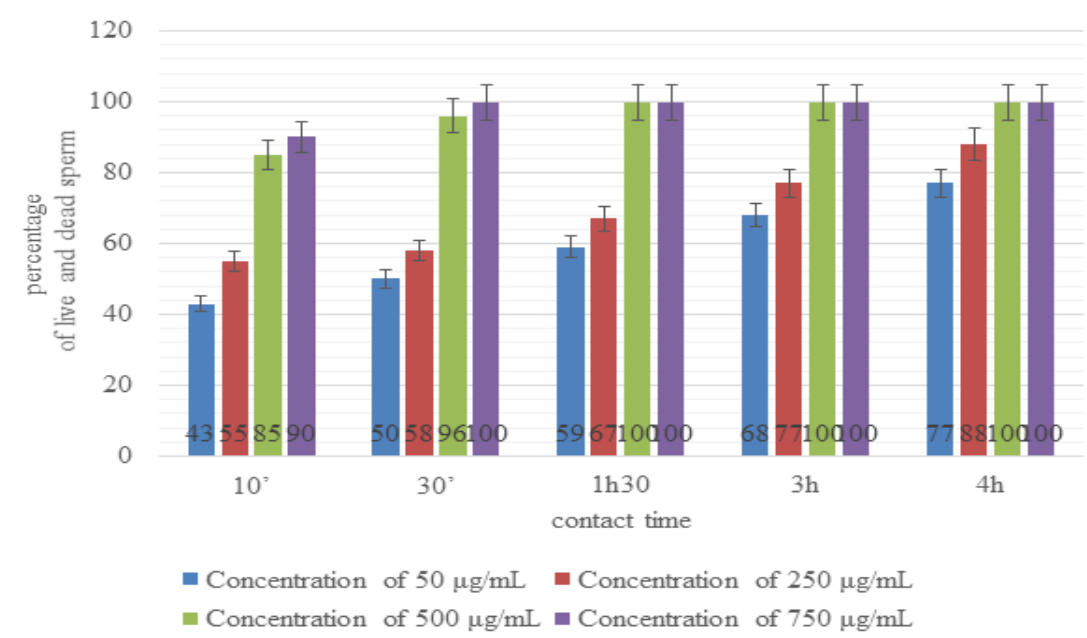

Figure 7. Evaluation of the vitality of the sperm as a function of time and the concentration of the extract of Herniaria glabra.

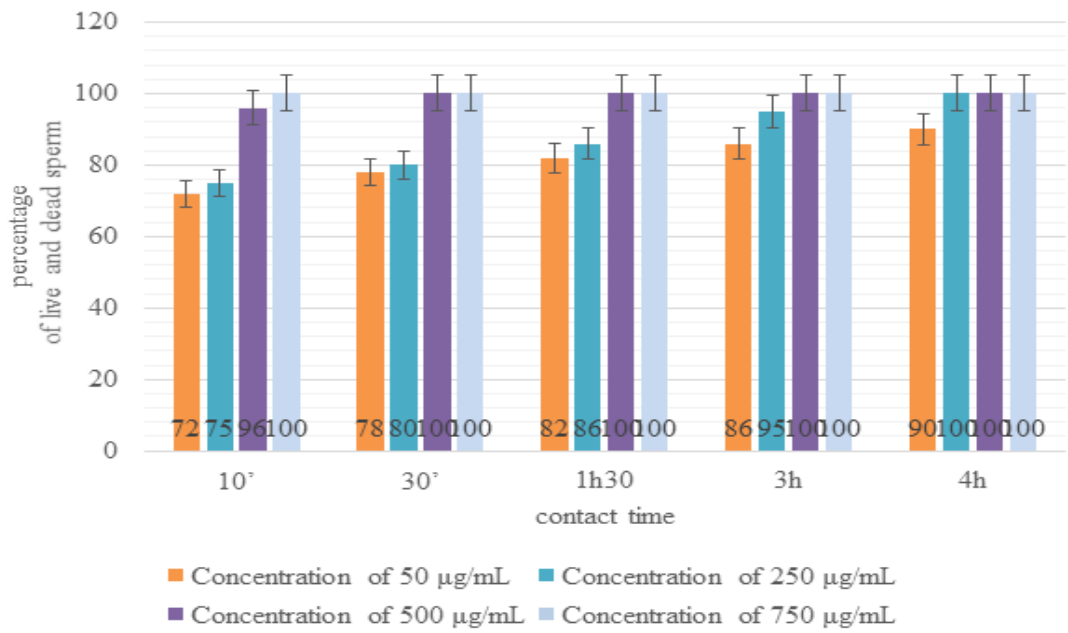

Figure 8. Evaluation of the vitality of the sperm as a function of time and the concentration of the extract of Saponaria officinalis.

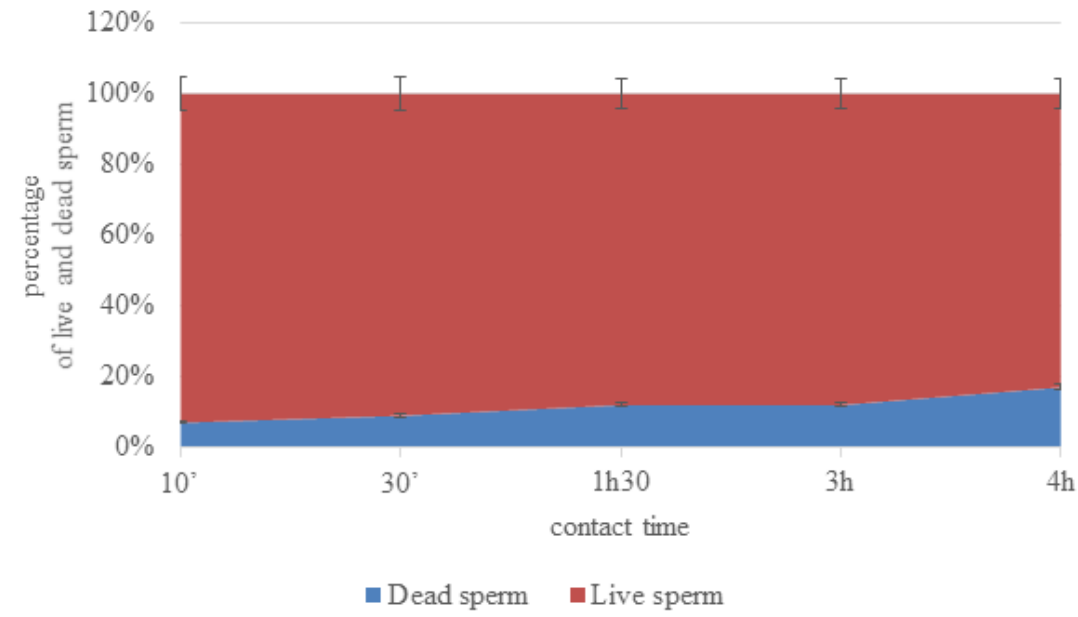

Figure 9. Evaluation of the vitality of the sperm as a function of the time for the control sample. 
For the extracts of Glycyrrhizia glabra (Figure 6), a concentration of $50 \mu \mathrm{g} / \mathrm{mL}$ caused the mortality of $86 \%$ of the spermatozoa after $4 \mathrm{~h}$. A concentration of $250 \mu \mathrm{g} /$ $\mathrm{mL}$, the mortality was $90 \%$. At the concentration of 500 $\mu \mathrm{g} / \mathrm{mL}$ or $750 \mu \mathrm{g} / \mathrm{mL}$, the mortality of the spermatozoa was complete in $90 \mathrm{~min}$.

For Herniaria glabra (Figure 7), a concentration of $750 \mu \mathrm{g} / \mathrm{mL}$ caused the mortality of $100 \%$ of the sperm after $30 \mathrm{~min}$. With a concentration of $500 \mu \mathrm{g} / \mathrm{mL}$, total inhibition was reached after $90 \mathrm{~min}$. On the other hand, the inhibition was never complete with low concentrations, it does not exceed $88 \%$ at the concentration of $250 \mu \mathrm{g} / \mathrm{mL}$, and $77 \%$ at the dose of $50 \mu \mathrm{g} / \mathrm{mL}$ after 4 hours.

With Saponaria officinalis (Figure 8), a mortality of $100 \%$ was reached after $10 \mathrm{~min}$ at a concentration of $750 \mu \mathrm{g} / \mathrm{mL}$. This same effect is achieved after $30 \mathrm{~min}$ with a concentration of $500 \mu \mathrm{g} / \mathrm{mL}$ and after $4 \mathrm{~h}$ at the concentration of $250 \mu \mathrm{g} / \mathrm{mL}$.

Compared to the control sample (sperm alone), there was a mortality rate of $7 \%$ after 10 min of incubation at $37^{\circ} \mathrm{C}$. Mortality is $17 \%$ after 4 hours (Figure 9 ).

\section{Discussion}

The objective of our work was to find alternative, natural spermicidal agents that can be used for the formulation of vaginal, well tolerated contraceptives. To this purpose, we evaluated the in vitro spermicidal activity, of three plants: Saponaria officinalis / Caryophyllaceae, Glycyrrhizia glabra / Fabaceae and Herniaria glabra / Caryophyllaceae. The presence of saponoside in our samples was made by determining the foam index. Effectively, a height of foam equivalent to $1 \mathrm{~cm}$ in the tube confirms the presence of saponoside. This height was found in tube number 5 for Glycyrrhizia glabra and in tubes number 4 for Saponaria officinalis and Herniaria glabra.

According to the results of our study, the saponins extracted from these plants cause significant sperm alteration. The immobilizing effect observed depends on the plants saponins extracts concentration and the time of sperm exposure to these extracts.

These results allowed us to evaluate, for the plants extracts studied the concentration range and the time interval needed to obtain a significant spermicidal effect.

For Saponaria officinalis, a concentration higher than $750 \mu \mathrm{g} / \mathrm{mL}$ seems to give an instantaneous effect (10 min) leading to a total immobility and non-vitality of the spermatozoa. This same effect is also observed after 30 minutes for a concentration of $500 \mu \mathrm{g} / \mathrm{mL}$. For Herniaria glabra, a concentration higher than $750 \mu \mathrm{g} / \mathrm{mL}$ gives a total spermicidal effect within $30 \mathrm{~min}$, both on the mobility and the vitality of the spermatozoa. For Glycyrrhizia glabra a concentration greater than $500 \mu \mathrm{g} / \mathrm{mL}$ results in a total spermicidal effect after $90 \mathrm{~min}$.

Our study found that sperm alteration by saponosides affects both mobility and vitality. Indeed, we found pink sperm, keeping an oscillating movement on the spot (after coloration with eosin). This allowed us to admit that, the saponins altered the functional integrity of the cell membrane of spermatozoa, without altering its structural organization. Such spermicides are likely to affect the membrane transport system. This results in a disturbance of the osmotic balance, which accelerates the entry of the dye (eosin) into the spermatozoa cells, before losing their mobility. This action on the sperm membrane results from the ease of saponosides to interact with cholesterol membranes [28]. Saponin-cholesterol complexes are indeed easily formed leading to membrane alteration [29]. The spermicidal effect is due to the modification of one of the key parameters of fertilization [28]. The formation of this complex disrupts the membrane permeability, causing either the selectivity of the membrane transport, or the loss of the biological activity of the sperm cell. [28-30]. According to several studies, this alteration can affect the head, the intermediate piece and the flagellum of sperm cells [31-33].

Spermicides are used as local, non-hormonal contraceptive methods [34]. The two main spermicidal molecules widely used are nonoxynol-9 and benzalkonium chloride [34]. They are chemical surfactants that reduce the surface tension of the sperm cell membrane, causing cell death by osmotic imbalance (destruction of the flagellum then bursting of the head) [34]. These spermicides have many side effects such as irritation, burning sensations and tingling [34]. In large doses, they cause ulcers, increasing the risk of sexually transmitted diseases $[6,34]$. The saponosides extracted from the plants studied have a spermicidal activity evidenced, depending on the plant used, within 10,30 or 90 min of contact time with normal sperm. The action of these substances takes place according to a well-defined mechanism of action, similar to that of chemical spermicides. They act by alteration of the plasma membrane and induce the death or immobilization of spermatozoa [34]. Also, according to previous works, these plants have no toxicity at low doses [21,35-38]. Their use could be suitable in particular when hormonal contraception is contraindicated and they also offer the advantage to be well tolerated and non-toxic, permitting to avoid the numerous side effects of chemical spermicides.

\section{Conclusion}

Our study revealed that the saponins contained in the three plants studied (Saponaria officinalis / Caryophyllaceae, Glycyrrhizia glabra / Fabaceae, and Herniaria glabra / Caryophyllaceae) proved to possess potent spermicidal effect. They can be used for contraception based on natural products formulations. These saponins extracted probably act by deterioration of the functional integrity of the spermatic plasma membrane. This alteration is due to the interaction of saponins with membrane lipids, causing its exaggerated permeabilization. 
Saponins are therefore natural products likely to be more active and less toxic than synthetic spermicides. These natural substances could replace nonoxynol-9 and other chemicals in vaginal contraceptives, especially for women in whom hormonal contraception is contraindicated.

\section{Acknowledgement}

We thank the "LABOMAC" laboratories for their invaluable contribution to this work.

\section{References}

1. Giami A. [Sexuality, health and human rights: invention of sexual rights]. Sexol. 2015;24:105-113. French. DOI: http:// dx.doi.org/10.1016/j.sexol.2015.07.003.

2. Kaunitz AM. Injectable contraception. New and existing options. Obstet Gynecol Clin North Am. 2000;27:741-780.

3. Roy G. Injectable contraception. Semin Reprod Med. 2010;28:126-132.

4. Collier F, Letombe B. [Natural and chemical contraception in women]. EMC Gynécologie. 1998;[738-A-11]:1-4. French

5. Bodet A. Histoire de la contraception, de la grossesse subie à la grossesse désirée. Thèse de doctorat [History of contraception, from passive to desired pregnancy. Doctoral thesis]. UFR sciences pharmaceutiques et ingénierie de la santé. Université Angers, 2014.

6. Hassoun D. [Methods of natural and barrier contraception, RPC CNGOF contraception]. Gynecol Obstet Fertil Senol. 2018;46:873-882. French. DOI: https://doi.org/10.1016/j. gofs.2018.10.002.

7. Faure M, Drapier-Faure E. [Novel contraceptions]. Ann Dermatol Venereol. 2006;133:292-295. French. DOI: 10.1016/s0151-9638(06)70900-0.

8. Findlay JA. Chemistry and Pharmacology of natural products: Saponins K. Hostettmann and A. Marston. Cambridge University Press, New York. J Nat Prod. 1996;59:1,96. https://doi.org/10.1021/np960011z.

9. Betina-Bencharif $\mathrm{S}$. Isolement et caractérisation de saponosides extraits de deux plantes médicinales Cyclamen africanum, Zygophyllum cornutum et évaluation de leurs activités anti-inflammatoire. Thèse de doctorat. [Isolation and characterization of saponoside extracts of two plants Cyclamen africanum, Zygophyllum cornutum and assessment of their anti-inflammatory activity. Doctoral thesis] Université de Bourgogne, Université MentouriConstantine 2014.

10. Wächter GA, Valcic S, Franzblau SG, Suarez E, Timmermann BN. Antitubercular activity of triterpenoids from Lippia turbinata. J Nat Prod. 2001;64:37-41.

11. Lacaille-Dubois MA, Hanquet B, Rustaiyan A, Wagner H. Squarroside A, a biologically active triterpene saponin from Acanthophyllum squarrosum. Phytochemistry. 1993;34:489495.

12. Gaidi G, Miyamoto T, Laurens V, Lacaille-Dubois MA. New acylated triterpene saponins from Silene fortunei that modulate lymphocyte proliferation. J Nat Prod. 2002;65:1568-1572.
13. Sparg SG, Light ME, van Staden J. Biological activities and distribution of plant saponins. J Ethnopharmacol. 2004;94:219-243.

14. Lin CY, Tsai CY, Lin SH. Effects of soy components on blood and liver lipids in rats fed high-cholesterol diets. World J Gastroenterol. 2005;11:5549-5552.

15. Saha P, Majumdar S, Pal D, Pal BC, Kabir SN. Evaluation of Spermicidal activity of MI-saponin A. Reprod Sci. 2010;17:454-464.

16. Garg S, Doncel G, Chabra S, Upadhyay SN, Talwar GP. Synergistic spermicidal activity of neem seed extract, reetha saponins and quinine hydrochloride. Contraception. 1994;50:185-190.

17. Bruneton J. Pharmacognosie, Phytochimie, Plantes médicinales [Pharmacognosy, phytochemistry, medicinal plants]. Lavoisier / Tech \& Doc. 5è éd. 2009. pp. 829-834.

18. Wichtl M, Anton R. Plantes thérapeutiques [Therapeutic plants]. Tec et Doc / EM inter. 2è éd., 2003. pp. 347-351.

19. Zhang Q, Ye M. Chemical analysis of the Chinese herbal medicine Gan-Cao (licorice). J Chromatogr A. 2009;1216:1954-1969.

20. World Health Organization. WHO monographs on selected medicinal plants. Vol. I, Geneva. Available at : https://apps. who.int/iris/bitstream/handle/10665/42052/9241545178.pdf ;jsessionid=B9AD8F9A381607CA52A4693335A33604?se quence $=1$.

21. Hmamouchi M. Les plantes médicinales et aromatiques marocaines [Moroccan medicinal and aromatic plants]. Imprimerie de Fédala. Mohammedia. 1999.

22. Jia Z, Koike K, Nikaido T. Saponarioside C, the first $\alpha$-D-galactose containing triterpenoid saponin, and five related compounds from Saponaria officinalis. J Nat Prod. 1999;62:449-453.

23. Künkele U, Lohmeyer TR. Plantes médicinales : identification, récolte, propriétés et emplois [Medicinal plants; identification, harvesting, properties and use]. Parragon Books Ltd. 2011.

24. Ghédira K, Goetz P. Herniaire: Herniaria glabra L. (Caryophyllaceae). Phytotérapie. 2017;15:300-303. https:// doi.org/10.1007/s10298-017-1168-2.

25. Soueges R. [Embryogenics of illecerbaceas, embryo development ofHernaria glabra]. L. Botany Letters. 1938;85:353-363. French. DOI: https://doi.org/10.1080/003 78941.1938.10834095.

26. Schröder H, Schubert-Zsilavecz M, Reznicek G, Cart J, Jurenitsch J, Haslinger E. A triterpene saponin from Herniaria glabra. Phytochemistry. 1993;34:1609-1613.

27. Mabry TJ, Markham KR, Thomas MB. The systematic identification of flavonoids. Springer-Verlag. Berlin 1970.

28. Rajasekaran M, Nair AG, Hellstrom WJ, Sikka SC. Spermicidal activity of an antifungal saponin obtained from the tropical herb Mollugo pentaphylla. Contraception. 1993;47:401-412.

29. Mitra S, Dungan SR. Micellar properties of quillaja saponin. 2. Effect of solubilised cholesterol on solution properties. Colloids and Surfaces B: Biointerfaces. 2000;17:117-133. 
30. Karabaliev M, Kochev V. Electrochemical investigations of cholesterol enriched glassy carbon supported thin lipid films. Biophys Chem. 2003;103:157-167.

31. Chakrabarti K, Pal S, Bhattacharyya AK. Sperm immobilization activity of Allium sativum L. and other plant extracts. Asian J Androl. 2003;5:131-135.

32. Paul D, Bera S, Jana D, Maiti R, Ghosh D. In vitro determination of the contraceptive spermicidal activity of a composite extract of Achyranthes aspera and Stephania hernandifolia on human semen. Contraception. 2006;73:284288.

33. Dhar JD, Bajpai VK, Setty BS, Kamboj VP. Morphological changes in human spermatozoa as examined under scanning electron microscope after in vitro exposure to saponins isolated from Sapindus mukorossi. Contraception. 1989;39:563-568.

34. Serfaty D. [Contraception for breastfeeding women: place of spermicides]. Journal de Gynécologie Obstétrique et Biologie de la Reproduction. 2015;44:18-27. French. DOI: https://doi.org/10.1016/j.jgyn.2014.07.001.

35. Sigurjonsdottir HA, Axelson M, Johannsson G, Manhem K, Nyström E, Wallerstedt S. The liquorice effect on the RAAS differs between the genders. Blood Press. 2006;15:169-172.

36. Ghedira K, Goetz P, Le Jeune R. Glycyrrhiza glabra L. (Fabaceae) Réglisse. Phytothérapie. 2010;8:185-90. https:// doi.org/10.1007/s10298-010-0556-7.

37. Rhiouani H, El-Hilaly J, Israili ZH, Lyoussi B. Acute and sub-chronic toxicity of an aqueous extract of the leaves of Herniaria glabra in rodents. J Ethnopharmacol. 2008;118:378-386.

38. Alexeeff GV, Broadwin R, Liaw J, Dawson SV. Characterization of the LOAEL-to-NOAEL uncertainty factor for mild adverse effects from acute inhalation exposures. Regul Toxicol Pharmacol. 2002;36:96-105. 